\title{
Stereotactic body radiotherapy (SBRT) for locally advanced intrahepatic and extrahepatic cholangiocarcinoma
}

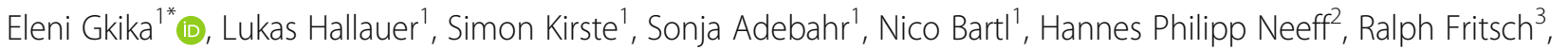
Volker Brass ${ }^{4}$, Ursula Nestle ${ }^{1,5,6,7}$, Anca Ligia Grosu ${ }^{1,5,6,7}$ and Thomas Baptist Brunner ${ }^{1,5,6,7}$

\begin{abstract}
Background: To evaluate the role of ablative radiotherapy doses in the treatment of hilar or intrahepatic cholangiocarcinoma (CCC) using stereotactic body radiotherapy (SBRT).

Methods: Consecutive patients treated from 2007 to 2016 with CCC were evaluated. Local control and toxicities were assessed every 3 months according to the Response Evaluation Criteria In Solid Tumors (RECIST) and the Common Terminology Criteria for Adverse Events v4.0, respectively. Overall survival (OS), local control (LC) and progression free survival were calculated from SBRT.

Results: Thirty seven patients with 43 lesions were retrospectively evaluated. The median dose delivered was 45 Gy (range 25-66 Gy) in 3-12 fractions, corresponding to a median equivalent dose in 2 Gy fractions (EQD2 10) of 56 (range 25-85) Gy. The median follow up was 24 months. The OS at 1 year was 56\% with a median OS of 14 (95\% Cl: 7.8-20.2) months from start of SBRT and 22 (95\% Cl: 17.5-26.5) months from diagnosis. Eight lesions progressed locally. The local control rate (LC) at 1 year was 78\%. The median progression free survival was 9 months (95\% Cl 2.8-15.2) 21 patients progressed in the liver but out of field and 15 progressed distantly. SBRT was well tolerated. Three patients (9\%) developed a Grade III bleeding. Seven patients developed a cholangitis, one due to progression and the other because of a stent dysfunction 2-21(median 8) months from SBRT.
\end{abstract}

Conclusion: In patients with locally advanced cholangiocarcinoma, SBRT is a local treatment option with an acceptable toxicity profile which warrants further investigation in prospective trials.

Keywords: SBRT, Stereotactic body radiotherapy, Intrahepatic and extrahepatic cholangiocarcinoma

\section{Background}

Cholangiocarcinoma (CCC) is the second most common primary liver cancer after hepatocellular carcinoma and is divided anatomically into intrahepatic (IHCC) and extrahepatic cholangiocarcinoma (EHCC). EHCCs are subdivided into hilar/perihilar (pCC, also called Klatskin tumors), or distal (dCC). pCC is the most common type of cholangiocarcinoma, followed by $\mathrm{dCC}$ and intrahepatic forms [1]. The only potentially curative treatment option is surgical resection but $70 \%$ of the patients are

\footnotetext{
*Correspondence: eleni.gkika@uniklinik-freiburg.de

'Department of Radiation Oncology, University Medical Centre Freiburg,

Freiburg im Breisgau, Germany

Full list of author information is available at the end of the article
}

deemed irresectable [2] and about half of the patients undergoing resection relapse within 1 year after resection [3]. The current standard of care for both locally advanced and metastatic patients with good performance status is combination chemotherapy with platinum and gemcitabine-containing protocols, which achieve a median overall survival of 11.7 and a median progression free survival of 8 months [4]. Currently primary treatment options for patients with unresectable or metastatic disease according to the National Comprehensive Cancer Network (NCCN) Guidelines version 1.2017 include: 1) clinical trial; 2) fluoropyrimidine-based or gemcitabine-based chemotherapy; or 3) best supportive care. In addition, fluoropyrimidine chemoradiation is included as an option for patients with unresectable 
disease. Locoregional therapies such as radiofrequency ablation (RFA) [5], trans-arterial chemoembolization (TACE) [6], drug-eluting bead trans-arterial chemoembolization (DEB-TACE) or TACE drug-eluting microspheres [7] and transarterial radioembolization (TARE) with yttrium-90 microspheres [8] have been shown to be safe and effective in a small retrospective series of patients with unresectable intrahepatic cholangiocarcinomas (NCCN version 1.2017, hepatobiliary cancers). Hepatic arterial infusion (HAI) chemotherapy also was used for the treatment of patients with advanced and unresectable intrahepatic cholangiocarcinoma [9]. Furthermore, liver transplantation was used in selected patients with locally advanced hilar cholangiocarcinomas [10] and the combination of photodynamic therapy (PDT) with biliary stenting was reported to be associated with prolonged OS in patients with unresectable cholangiocarcinoma in small randomized clinical trials [11].

The role of radiotherapy remains controversial due to lack of phase III randomised trials. However, several early phase studies have suggested that radiotherapy can prolong survival $[12,13]$, and there is evidence of a dose response relationship [12, 14]. This has prompted the investigation of SBRT as a method for dose-escalation. SBRT is an emerging treatment technique for cholangiocarcinoma where ablative doses can be applied with a steep dose gradient and thus sparing normal tissue. SBRT can lead to high local control rates with moderate toxicity in other primary or metastatic cancers of the liver $[15,16]$.

In this study, we evaluated the role of SBRT in the treatment of CCC in respect to toxicity as well as local control.

\section{Methods}

\section{Patients}

After institutional review board approval we retrospectively analysed 37 consecutive patients treated at our centre with SBRT, either for positive margins after resection or for inoperable or recurrent, locally advanced CCC. All patients included in the analysis underwent multidisciplinary evaluation by medical, surgical and radiation oncologists.

Patients underwent clinical examinations and routinely laboratory tests before treatment and at least weekly during treatment, by the radiation oncologists of the department. During follow up, physical examination, blood tests and computed tomography (CT) or magnetic resonance imaging (MRI) were acquired every 3 months. Toxicity was scored using the NCI Common Terminology Criteria for Adverse Events v4.0. (National Cancer Institute: Common Terminology Criteria for Adverse Events Version 4.03, CTCAE 2010). All toxicities that were observed within 90 days after treatment were considered to be acute; all other toxicities reported after $>90$ days were considered to be late.

Primary end points were toxicity and local control (LC) in the planning target volume (PTV, or 'in-field') at 1 year; the latter was defined as the absence of progressive disease within the PTV as per Response Evaluation Criteria in Solid Tumors (RECIST) v1.1 [17]. Secondary end points were overall survival and patterns of failure. Lesions that progressed outside the PTV in the liver or lymph nodes were scored as regional progression and those developed in other organs as distant progression.

\section{SBRT techniques}

Patients were immobilized in supine position with a customized vacuum cushion using abdominal compression to minimize respiratory motion and underwent a 4 dimensional-CT (4D CT) or 4D fluorodeoxyglucose positron emission tomography (FDG PET/CT), as described elsewhere [18]. The gross tumor volume (GTV) was defined based on available imaging including the finding of the Endoscopic Retrograde Cholangiopancreatography (ERCP), Magnetic Resonance Cholangiopancreatography (MRCP), MRI, CT and/or PET CT. The internal target volume (ITV) was created accounting for the extent and the position of the tumour at all motion phases in 3 dimensions of the $4 \mathrm{D}-\mathrm{CT}$ or $4 \mathrm{D}-\mathrm{PET} / \mathrm{CT}$. The PTV was a uniform $4 \mathrm{~mm}$ expansion of the ITV in all dimensions. Organs at risk (OAR) included heart, liver, lung, ribs, skin, spinal cord, stomach, small intestine, colon, duodenum, kidneys, bile duct and large vessels were defined as applicable. Dose constraints were defined according to Timmerman et al. [19].Patients were treated with 3 to 12 fractions delivered every other day, depending on the proximity to OARs, mostly the stomach and the intestine. Three fraction regimens (typically $3 \times 12.5 \mathrm{~Gy}$ ) were preferred in patients with lesions at distance from critical structures, 12 fraction regimens (typically $12 \times 4-5.5$ Gy) were preferred in patients with direct contact to OARs, and 5 fraction regimens (typically $5 \times 7-10 \mathrm{~Gy}$ ) in all other cases, so that the dose constraints could be respected. From 2007 to 2013 treatment was prescribed either to the $60 \%$ or $80 \%$ encompassing isodose and thereafter according to ICRU report 83. For lesions where dose constraints for the OARs could not be achieved, we used a simultaneous integrated protection (SIP) dose prescription, instead of reducing the dose to the entire PTV. The SIP approach is an intensity modulated radiotherapy (IMRT) technique described in detail elsewhere [20]. For the analysis, the prescribed doses, as well as the maximum and mean dose delivered were converted to equieffective doses for 2 Gy fractions (EQD2), assuming that tumour, late reacting bowel tissue and liver $\alpha / \beta$ ratios were $10 \mathrm{~Gy}, 3$ Gy and 2 Gy, respectively [21]. 
For all patients a daily on-line correction using cone beam computed tomography (CBCT) scans was applied and oral contrast was given to visualise stomach and/or duodenum in cases of close proximity.

\section{Statistical analysis}

Descriptive statistics were used to analyse patient, tumor and treatment characteristics. Survival and control times were calculated from the start of SBRT. Time to progression and survival were assessed using the KaplanMeier method and the Cox proportional hazards model. Analyses were performed using SPSS (SPSS Inc., Chicago, IL) Statistical significance was set to $p \leq .05$ and two sided.

\section{Results}

\section{Patient, tumor and treatment characteristics}

Between 2007 and 2016, 37 patients with 43 lesions were treated with SBRT at our institute. Patient and tumor characteristics are summarised in Table 1. Seventeen lesions were identified as intrahepatic (IHCC) and 26 as extra-hepatic CCC (EHCC). Twenty six patients had a primarily inoperable disease, three patients were treated for positive margins and eight patients were treated for locoregional relapse after resection. Four patients had distant metastases, prior to SBRT, which were treated with chemotherapy $(n=3)$ or Radiofrequency Ablation (RFA, $n=1$ ). These patients were treated either as oligometastatic or for oligoprogression. Twenty one patients (57\%) had biliary stents prior to treatment. The median bilirubin concentration before treatment was $0.8 \mathrm{mg} / \mathrm{dl}$ (range: 0.2-21). Twenty patients had FDG-PET/CT prior to treatment as part of the initial staging or treatment planning. The median tumor diameter was $4.9 \mathrm{~cm}$ (range 2-18) with a median PTV volume of $124 \mathrm{~cm}^{3}$ (range 91356) and a median liver volume of $1576 \mathrm{~cm}^{3}$ (range 843-3355).

Median prescription dose was 45 (38-48) Gy corresponding to a median EQD2 10 of 56 (range 25-61) Gy using a median dose per fraction of 4 Gy (range 412.5 Gy) in 3 to 12 fractions. Sixteen patients were treated with simultaneous integrated protection (SIP). Treatment characteristics are summarised in Table 1.

\section{Toxicity}

Overall treatment was well tolerated. Three patients (9\%) developed a Grade III bleeding. The first patient developed a gastric bleeding 4.3 months after SBRT and was treated with argon plasma coagulation. The dose maximum $\left(D_{\max }\right)$ at the stomach was 45.6 Gy in 12 fractions, the Dose at $0.5 \mathrm{~cm}^{3}\left(D_{0.5}\right)$ was 43.7 Gy and at $5 \mathrm{~cm}^{3}\left(D_{5}\right)$ was $40 \mathrm{~Gy}$. The second patient was diagnosed with massive progression with ascites and peritoneal dissemination 3.7 months after SBRT and developed gastrointestinal bleeding. The patient refused esophagogastroduodenoscopy und thus the
Table 1 Patient and treatment characteristics

\begin{tabular}{|c|c|}
\hline Parameter & $\mathrm{Nr}$ \\
\hline \multicolumn{2}{|l|}{ A. Patient and tumor characteristics } \\
\hline Age (years) Median (range) & $67(36-87)$ \\
\hline \multicolumn{2}{|l|}{ Gender } \\
\hline Male & $24(56 \%)$ \\
\hline Female & $19(44 \%)$ \\
\hline \multicolumn{2}{|l|}{ Tumor location $^{a}$} \\
\hline IHCC & $17(40 \%)$ \\
\hline EHCC & $26(60 \%)$ \\
\hline \multicolumn{2}{|l|}{ Treatment } \\
\hline Primary inoperable & $26(70 \%)$ \\
\hline Recurrent & $8(22 \%)$ \\
\hline Positive margins & $3(08 \%)$ \\
\hline \multicolumn{2}{|l|}{ Prior therapies } \\
\hline Resection & $12(32 \%)$ \\
\hline Chemotherapy & $6(16 \%)$ \\
\hline Gemcitabine/Oxaliplatin & 1 \\
\hline Gemcitabine & 1 \\
\hline Capecitabin & 1 \\
\hline $5-\mathrm{FU}$ & 1 \\
\hline \multicolumn{2}{|l|}{ Therapies after SBRT } \\
\hline Chemotherapy & $13(35 \%)$ \\
\hline TACE & $1(03 \%)$ \\
\hline CA 19-9 (U/ml) Median (IQR) & 149 (20-499) \\
\hline Bilirubin (mg/dl) Median (range) & $0.8(0.5-21)$ \\
\hline GTV Diameter $(\mathrm{cm})^{\mathrm{a}}$ Median (IQR) & $4.9(3.4-8.2)$ \\
\hline PTV Volume $\left(\mathrm{cm}^{3}\right)^{\mathrm{a}}$ Median (IQR) & $124(60-329)$ \\
\hline \multicolumn{2}{|l|}{ B. Treatment characteristics } \\
\hline \multicolumn{2}{|l|}{ Prescribed dose $(G y)^{a}$} \\
\hline Median (IQR) & $45(38-48)$ \\
\hline \multicolumn{2}{|l|}{ Maximum point dose (Gy) ${ }^{a}$} \\
\hline Median (IQR) & $51(44-58)$ \\
\hline \multicolumn{2}{|l|}{ Mean PTV dose (Gy) ${ }^{a}$} \\
\hline Median (IQR) & $47(42-51)$ \\
\hline \multicolumn{2}{|l|}{$\mathrm{EQD} 2_{10}(\mathrm{~Gy})^{\mathrm{a}}$} \\
\hline Median (IQR) & $56(47-61)$ \\
\hline \multicolumn{2}{|l|}{ EQD2 10 Maximum point dose (Gy) } \\
\hline Median (IQR) & $65(59-85)$ \\
\hline \multicolumn{2}{|l|}{ EQD2 10 Mean dose (Gy) } \\
\hline Median (IQR) & $63(53-82)$ \\
\hline
\end{tabular}

IHCC Intrahepatic cholangiocarcinoma, EHCC Extrahepatic cholangiocarcinoma, 5-FU 5-Fluoruracil, IQR interquartile range, EQD2 equieffective doses in $2 \mathrm{~Gy}(\alpha / \beta=10)$

aper lesion 
exact location of the bleeding could not be identified. The patient was under oral coagulation due to a pulmonary embolism. This patient died shortly after refusing any medical intervention. The maximum point dose $\mathrm{D}_{\max }$ was $39.4 \mathrm{~Gy}$ in 12 fractions, the $\mathrm{D}_{0.5 \mathrm{~cm}}^{3}$ was 25,3 Gy and at $5 \mathrm{~cm}^{3} \mathrm{D}_{5 \mathrm{cc}}$ was $21 \mathrm{~Gy}$. The dose at the stomach was moderate so that one could hypothesize that the bleeding was caused due to portal hypertension because of ascites due to massive progression. The last patient developed a duodenal ulceration with bleeding after frequent biliary stenting due to tumor progression 12.6 months after SBRT. $\mathrm{D}_{\max }$ at the duodenum was 25 Gy in 10 fractions. Institutional dose constraints for stomach and duodenum are shown in Table 2 including conversion to EQD2 3 , using an $\alpha / \beta=3$ to account for late reacting normal tissue. None of the delivered doses to the specific OARs exceeded the institutional dose constraints. Seven patients developed a cholangitis, one due to a local progression which required stenting and all other patients because of a stent dysfunction which resolved after stent replacement.

\section{Local control and patterns of failure}

The median follow up for patients alive was 24 months. The local control (LC) at 1 year was $78 \%$ and $58 \%$ at 2 years (Fig. 1). Median progression free survival (PFS) was 9 months (95\% CI 2.8-15.1) from SBRT start, with a PFS at 1 and 2 years of $47 \%$ and 19\%, respectively. Eight lesions progressed in field. Twenty one patients progressed in the liver but out of field (three of them with synchronous local lymph nodes) and 15 progressed distantly (Fig. 2). None of the regional progressions were marginal recurrences. Sites of distant progression were lung $(n=2)$, spleen $(n=1)$, peritoneal dissemination $(n=9)$, bones $(n=3)$. Thirteen patients were treated with chemotherapy after SBRT and one was treated with TACE. None of the variables tested (Table 3) correlated with local control, neither biological equivalent dose (BED) more than 100 Gy or 80.5 Gy as proposed by Tao et al. [12] or above the median at the encompassing isodose, at the maximum point dose or at the mean PTV.

\section{Survival outcomes}

The median overall survival (OS) was 14 (95\% CI: 7.820.2) months from start of SBRT and 22 (95\% CI: 17.526.5) months from diagnosis. The OS from SBRT at 1 and 2 years was $57 \%$ and $25 \%$ (Fig. 3), respectively.

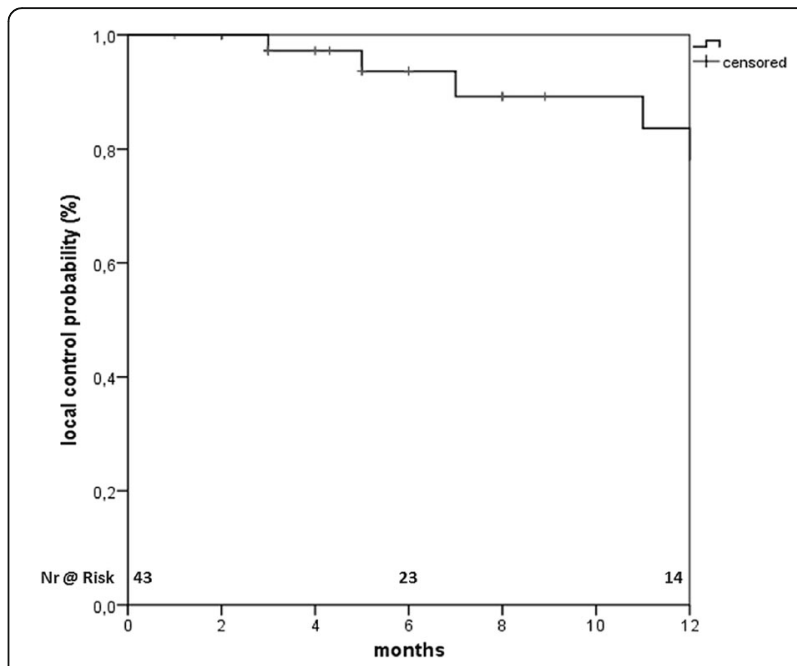

Fig. 1 Local control from the start of radiotherapy

Eighteen patients died due to tumor progression, seven of unknown causes and two due to other causes. None of the patients died from therapy related cholangiosepsis. One developed a liver abscess, which was not associated with SBRT as it developed more than $3.5 \mathrm{~cm}$ from the edge of the PTV, after a biliary stent replacement 20 months after SBRT and died due to a bacterial peritonitis. Patients with prior metastases had a worse survival (14 vs 4 months, $p=0.2$ ) but not statistically significant. Furthermore neither pre-treatment chemotherapy, nor pre-treatment CA 19-9 or bilirubin concentrations correlated with the OS on univariate and multivariate analysis.

\section{Discussion}

Our institution has previously reported outcomes on the role of SBRT [22, 23]. In this study, we present the results of SBRT in both IHCCC and EHCCC in one of the largest series reported for $\mathrm{CCC}$ and especially for EHCC (Table 4).

In the definitive and palliative setting, concurrent chemoradiation leads to a median OS of 2.2- 27 months and $3 y$-years survival rates ranging from 6 to 73 months [24]. Local recurrence is the primary site of progression and dose escalation seems to be promising in terms of LC and OS. In a retrospective series using different fractionation regimes, Tao et al. could show that a BED

Table 2 Correlation of toxicity with the maximum point dose delivered at the OAR and the institutional constraints

\begin{tabular}{lllllll}
\hline Toxicity & Nr of Fractions & OAR & Dmax (Gy) delivered & EQD2 3 (Gy) delivered & $\begin{array}{l}\text { Dmax constraint (Gy) } \\
\text { for the OAR }\end{array}$ & $\begin{array}{c}\text { EQD2 } \\
\text { constraint }\end{array}$ \\
\hline Gastric bleeding & 12 & stomach & 45.6 & 62 & 47.4 & 65.8 \\
Gl bleeding & 12 & stomach & 39.4 & 49.5 & 47.4 & 65.8 \\
Duodenal ulceration & 10 & duodenum & 25 & 27.5 & 44.3 & 65.8 \\
\hline
\end{tabular}

$O A R$ organ at risk, $E Q D 2_{3}$ equieffective doses in $2 \mathrm{~Gy}(\mathrm{a} / \beta=3)$, $\mathrm{Gl}$ gastro-intestinal, Dmax maximum point dose 


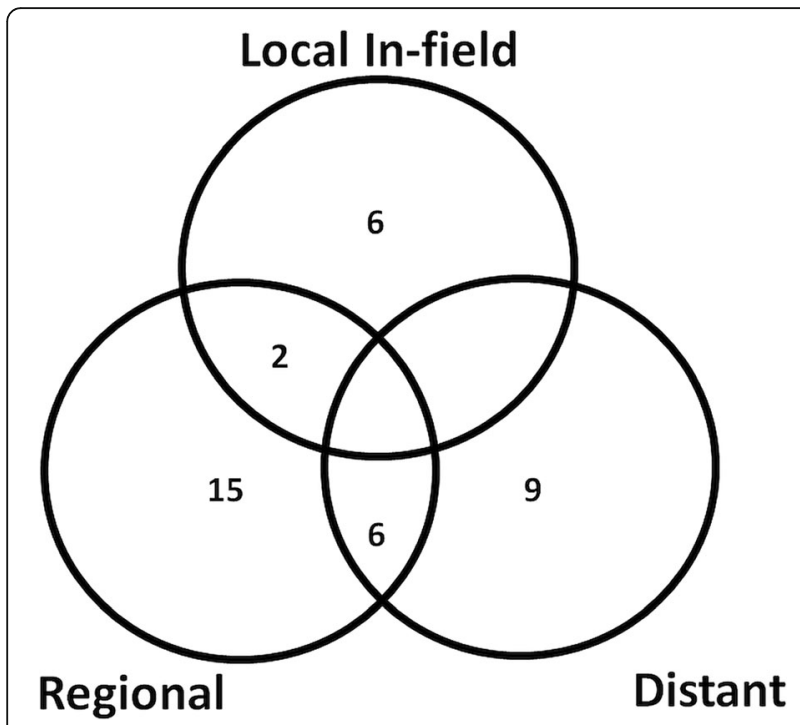

Fig. 2 Venn diagram showing the patterns of relapse

greater than 80.5 Gy correlated with prolonged OS and LC $(p=0.017$ and $p=0.04$ respectively).These results, could not be reproduced in another retrospective study from Jung et al. [25] who treated patients using SBRT in 1-5 fraction. In his study a BED higher than 86 Gy did not correlate with better LC or survival $(p=0.4$ and $p=$ 0.1 respectively) which is in concordance with our findings. Furthermore, Jung et al. did not find any differences between patients treated for IHCCC $(n=33)$ vs EHCCC $(n=25)(p=0.54)$ but they reported in $10 \%$ of the patients grade $\geq 3$ complications such as duodenal and gastric ulceration and perforation as well as cholangitis and bile duct stenosis. Sandler et al. [26] reported $16 \%$ grade $\geq 3$ toxicities in a retrospective analysis with 31 patients $(\mathrm{IHCCC}=6, \mathrm{EHCCC}=25)$ treated with SBRT. Similar toxicities were also reported in a study of Kopek et al. [27] who treated 26 patients with Klatskin tumors. In this study, six patients developed a duodenal ulceration and 3 a duodenal stenosis (two of whom were among those with severe ulcers). They reported that the mean dose to $1 \mathrm{~cm}^{3}$ of duodenum (D $1 \mathrm{~cm}^{3}$ ) was significantly higher for patients developing grade $\geq 2$ ulceration or stenosis at $37.4 \mathrm{~Gy}$ ( $83 \%$ of prescription dose) versus 25.3 Gy $(p=0.03)$ which corresponds to an EQD2 ${ }_{3}$ of 115 Gy and 57.8 Gy, respectively. Kopek and co-workers suggested a $V_{21 G y} \leq 1 \mathrm{~cm}^{3}$ as a dose constraint for the duodenum in 3 fractions which corresponds to an EQD2 $2_{3}$ of 42 Gy.

The increased toxicity in these studies is probably due to the large proportion of EHCCC included, because of the vicinity of these tumors with the duodenum. The above mentioned studies, together with the current one, are the largest reported series for EHCC (Table 4). In our series we had less late toxicities (3 cases of gastrointestinal bleeding), two of which could be explained due to other causes, such portal hypertension due to massive tumour progression and ascites and in the second case due to the manipulation after frequent biliary stenting. In both cases the institutional dose constraints were respected with a maximal EQD2 ${ }_{3}$ point dose significantly less than $65.8 \mathrm{~Gy}$. We could show a favourable toxicity profile probably due to a moderate fractionation and the use of simultaneous integrated protection (SIP). This concept is being further evaluated in a prospective trial.

To date, the role of SBRT is not clearly established, but there is emerging evidence that SBRT could lead to an improved OS, LC and symptom control. Preliminary results on SBRT [22, 28, 29] have reported promising median OS rates ranging from 28.6-35.5 moths. These results could not be confirmed in subsequent analyses which included a higher number of patients $[25,26,30]$. Although all of these studies including the current one have several limitations such as the retrospective design and small sample size median OS rates of 10-17 months

Table 3 Univariate analysis for local control and overall survival

\begin{tabular}{|c|c|c|c|c|}
\hline \multirow[b]{2}{*}{ Variable } & \multicolumn{2}{|l|}{ Local control } & \multicolumn{2}{|l|}{ Overall survival } \\
\hline & $\mathrm{HR}(95 \% \mathrm{Cl})$ & $p$ & $\mathrm{HR}(95 \% \mathrm{Cl})$ & $p$ \\
\hline Location§ & $0.554(0.111-2.772)$ & 0.472 & $0.847(0.4364-1.970)$ & 0.700 \\
\hline GTV diameter (cm) & $0.809(0.613-1.068)$ & 0.135 & 1.005 (0.900-1.122) & 0.933 \\
\hline CA 19-9 (U/ml) & $1.000(1.000-1.001)$ & 0.506 & $1.000(1.000-1.000)$ & 0.113 \\
\hline Bilirubin (mg/dl) & $1.003(0.838-1.201)$ & 0.972 & 0.970 (0.861-1.093) & 0.618 \\
\hline PTV Volume $\left(\mathrm{cm}^{3}\right)$ & $0.997(0.992-1.001)$ & 0.163 & $1.000(0.999-1.002)$ & 0.892 \\
\hline Prescribed dose (Gy) & $0.749(0.461-1.217)$ & 0.243 & $0.994(0.938-1.052)$ & 0.823 \\
\hline Maximum dose (Gy) & 0.997 (0.907-1.094) & 0.940 & $0.983(0.939-1.029)$ & 0.455 \\
\hline Mean dose (Gy) & $1.060(0.952-1.180)$ & 0.286 & $0.991(0.937-1.048)$ & 0.750 \\
\hline EQD2 10 prescribed (Gy) & $1.007(0.938-1.081)$ & 0.844 & $0.984(0.944-1.025)$ & 0.440 \\
\hline EQD2 ${ }_{10}$ Maximum (Gy) & $0.975(0.940-1.012)$ & 0.184 & $0.996(0.977-1.017)$ & 0.723 \\
\hline EQD2 10 Mean (Gy) & $0.971(0.933-1.012)$ & 0.148 & $0.993(0.973-1.013)$ & 0.474 \\
\hline
\end{tabular}




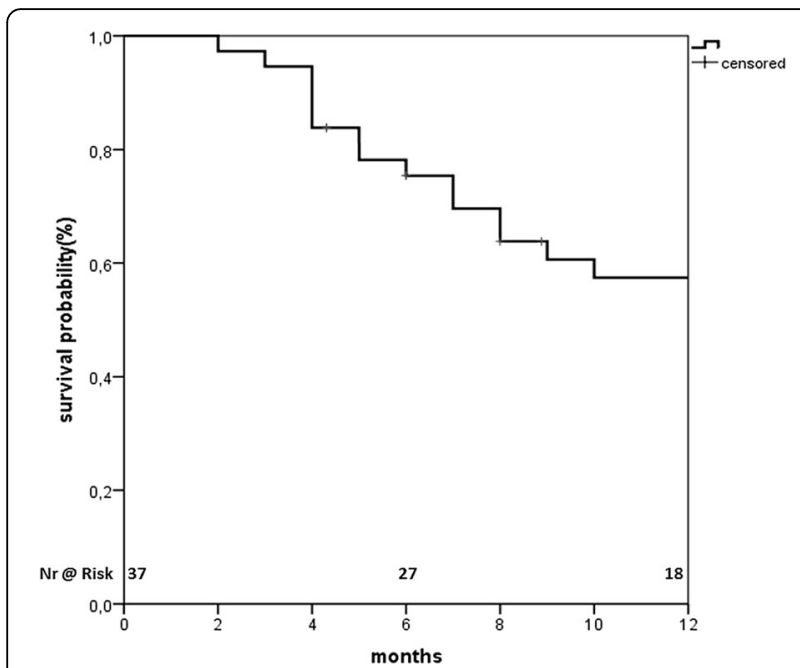

Fig. 3 Overall survival from the start of radiotherapy and LC rates at 1 year of $55-100 \%$ seem highly promising in patients with inoperable or recurrent cholangiocarcinoma. In patients who receive chemotherapy receipt of radiotherapy was associated with improved survival [31]. SBRT can be well integrated to systemic chemotherapy with minimal interruption delivering an effective local treatment. Furthermore, radiotherapy does not show relevant impairment of the quality of life [32, 33] with the only observed deficits being temporary worsening of appetite and fatigue. Patients with advanced CCC and higher bilirubin concentrations are not candidates for chemotherapy and the only alternative is best supportive care. In our study those patients had a median OS of 12 months, higher than the rest, probably also due to patient selection bias, yet with a certain profit from SBRT in comparison to best supportive care. Stereotactic body radiation therapy is well tolerated and warrants further evaluation.

\section{Conclusion}

Patients with cholangiocarcinoma, who are not candidates for surgical resection, have a dismal prognosis, and may benefit from locally ablative techniques such as SBRT.

Table 4 Review of literature on SBRT

\begin{tabular}{|c|c|c|c|c|c|c|c|c|}
\hline Authors & Study & Localization & $\begin{array}{l}\text { Nr. of } \\
\text { Lesions }\end{array}$ & $\begin{array}{l}\text { Nr. of } \\
\text { Fractions }\end{array}$ & Total Dose (Gy) & $\begin{array}{l}\text { LC @ } \\
1 \text { year }\end{array}$ & $\begin{array}{l}\text { Median OS } \\
\text { (months) }\end{array}$ & $\begin{array}{l}\text { Late } \\
\text { Toxicity }\end{array}$ \\
\hline Tse [34] & $P$ & $\begin{array}{l}\text { IHCC } \\
\text { EHCC }\end{array}$ & $\begin{array}{l}10 \\
0\end{array}$ & 6 & $28-48$ & $65 \%$ & 15 & $\begin{array}{l}1 \text { biliary obstruction } \\
1 \text { bowel obstruction }\end{array}$ \\
\hline Goodman [29] & P & $\begin{array}{l}\text { IHCC } \\
\text { EHCC }\end{array}$ & $\begin{array}{l}5 \\
0\end{array}$ & 1 & $18-30$ & $77 \%$ & 28.6 & None \\
\hline Polistina [28] & $\mathrm{R}$ & $\begin{array}{l}\text { IHCC } \\
\text { EHCC }\end{array}$ & $\begin{array}{l}0 \\
10\end{array}$ & 3 & $30^{a}$ & $80 \%{ }^{\mathrm{b}}$ & 35.5 & $\begin{array}{l}1 \text { ulceration } \\
2 \text { stenosis }\end{array}$ \\
\hline Ibarra [35] & $\mathrm{R}$ & $\begin{array}{l}\mathrm{IHCC} \\
\mathrm{EHCC}\end{array}$ & $\begin{array}{l}11 \\
0\end{array}$ & 3 & $22-50$ & $55.5 \%$ & 11 & 3 Grad 3 \\
\hline Barney [36] & $\mathrm{R}$ & $\begin{array}{l}\text { IHCC } \\
\text { EHCC }\end{array}$ & $\begin{array}{l}6 \\
4\end{array}$ & $3-5$ & $45-60$ & $100 \%$ & 15.5 & 1 Grade 3 biliary stenosis, 1 Grade 5 liver failure \\
\hline Momm [22] & $\mathrm{R}$ & $\begin{array}{l}\text { IHCC } \\
\text { EHCC }\end{array}$ & $\begin{array}{l}0 \\
13\end{array}$ & $10-12$ & $32-56$ & $78 \%$ & 33.5 & $\begin{array}{l}1 \text { Grade } 3 \\
5 \text { cholangitis }\end{array}$ \\
\hline Weiner [37] & P & $\begin{array}{l}\text { IHCC } \\
\text { EHCC }\end{array}$ & $\begin{array}{l}12 \\
0\end{array}$ & 5 & $40-55$ & $91 \% \S$ & 13.2 & $\begin{array}{l}1 \text { hepatic failure§ } \\
1 \text { biliary stricture }\end{array}$ \\
\hline Kopek [27] & $\mathrm{R}$ & $\begin{array}{l}\text { IHCC } \\
\text { EHCC }\end{array}$ & $\begin{array}{l}26 \\
1\end{array}$ & 3 & 45 & $85 \%$ & 10.6 & $\begin{array}{l}6 \text { ulcerations } \\
3 \text { stenosis }\end{array}$ \\
\hline $\begin{array}{l}\text { Mahadevan } \\
{[30]}\end{array}$ & $\mathrm{R}$ & $\begin{array}{l}\text { IHCC } \\
\text { EHCC }\end{array}$ & $\begin{array}{l}31 \\
11\end{array}$ & $3-5$ & $24-45$ & $88 \%$ & 17 & 4 Grade 3 (ulceration, cholangitis, abscess) \\
\hline Sandler [26] & $\mathrm{R}$ & $\begin{array}{l}\text { IHCC } \\
\text { EHCC }\end{array}$ & $\begin{array}{l}6 \\
25\end{array}$ & 5 & 40 & $78 \%$ & 15.7 & 5 Grade $\geq 3$ \\
\hline Jung [25] & $\mathrm{R}$ & $\begin{array}{l}\text { IHCC } \\
\text { EHCC }\end{array}$ & $\begin{array}{l}33 \\
25 \pm\end{array}$ & $1-5$ & $15-60$ & $85 \%$ & 10 & $\begin{array}{l}6 \text { Grade } 3 \text { (ulceration, cholangitis, stenosis, } \\
\text { perforation) }\end{array}$ \\
\hline Current & $\mathrm{R}$ & $\begin{array}{l}\text { IHCC } \\
\text { EHCC }\end{array}$ & $\begin{array}{l}17 \\
26\end{array}$ & $3-12$ & $21-66$ & $78 \%$ & 14 & 3 Grade $\geq 3$ \\
\hline
\end{tabular}

$R$ retrospective, $P$ prospective, $I H C C C$ intrahepatic cholangiocarcinoma, EHCCC extrahepatic cholangiocarcinoma

${ }^{b}$ local response ratio

\pm 5 patients treated with conventional fractionation with a stereotactic boost

$\S$ In this study SBRT was performed also in patients with hepatocellular carcinoma. LC and toxicities are reported for the whole group of patients including hepatocellular and cholangiocarcinoma 
SBRT is a local treatment option with an acceptable toxicity profile, allowing its integration into multimodal treatment concepts. Prospective trials to validate these findings are underway.

\section{Abbreviations}

CBCT: Cone beam computed tomography; CCC: Cholangiocarcinoma; CT: Computed tomography; CTCAE: Common terminology criteria for adverse events; dCC: Distal Cholangiocarcinoma; DEB-TACE: Drug-eluting bead trans-arterial chemoembolization; EHCC: Extrahepatic cholangiocarcinoma; EQD2: Equivalent dose in 2 Gy fractions; ERCP: Endoscopic retrograde cholangiopancreatography; FDG PET/ CT: Fluorodeoxyglucose positron emission tomography; GTV: Gross tumor volume; HAl: Hepatic arterial infusion; ICRU: International commission on radiation units and measurements; IHCC: Intrahepatic cholangiocarcinoma; IMRT: Intensity modulated radiotherapy; ITV: Internal target volume; LC: Local control; MRCP: Magnetic resonance cholangiopancreatography; MRI: Magnetic resonance imaging; NCCN: National comprehensive cancer network; NCl: National Cancer Institute; OAR: Organs at risk; OS: Overall survival; pCC: Hilar/Perihilar cholangiocarcinoma; PDT: Photodynamic therapy; PTV: Planning target volume; RECIST: Response evaluation criteria in solid tumors; RFA: Radiofrequency ablation; SBRT: Stereotactic body radiotherapy; SIP: Simultaneous integrated protection; TACE: Trans-arterial chemoembolization; TARE: Transarterial radioembolization

\section{Acknowledgements}

Not applicable

\section{Funding}

No funding.

\section{Availability of data and materials}

The datasets used and/or analysed during the current study are available from the corresponding author on reasonable request.

\section{Authors' contributions}

EG, TB made substantial contributions to conception and design, the acquisition of data, analysis the interpretation of data and the drafting the manuscript. LH made substantial contributions in the acquisition of data and analysis. EG, LH, SK, SA, NB, HPN, RF, VB, UN, ALG, TBB made substantial contributions in interpretation of data and have revised it critically for important intellectual content. All authors have given final approval of the version to be published. Each author have participated sufficiently in the work to take public responsibility for appropriate portions of the content and agreed to be accountable for all aspects of the work in ensuring that questions related to the accuracy or integrity of any part of the work are appropriately investigated and resolved.

\section{Ethics approval and consent to participate}

The study was approved by the ethics committee of the University Hospital of Freiburg (No 519/16, date of approval: 27.10.2016) and was carried out in accordance with the Declaration of Helsinki, and the requirement for informed consent was waived because of the retrospective design.

\section{Consent for publication}

Not applicable.

\section{Competing interests}

The authors declare that they have no competing interests.

\section{Publisher's Note}

Springer Nature remains neutral with regard to jurisdictional claims in published maps and institutional affiliations.

\section{Author details}

'Department of Radiation Oncology, University Medical Centre Freiburg, Freiburg im Breisgau, Germany. ${ }^{2}$ Department of General and Visceral Surgery, University Medical Centre Freiburg, Freiburg im Breisgau, Germany. ${ }^{3}$ Department of Internal Medicine, Haematology, Oncology and Stem-Cell Transplantation, University Medical Centre Freiburg, Freiburg im Breisgau,
Germany. ${ }^{4}$ Department of Gastroenterology, Hepatology, Endocrinology and Infectious Diseases, University Medical Centre Freiburg, Freiburg im Breisgau, Germany. ${ }^{5}$ German Cancer Consortium (DKTK), partner site Freiburg, Heidelberg, Germany. ${ }^{6}$ German cancer Research Centre (DKFZ), Heidelberg, Germany. ${ }^{7}$ Faculty of Medicine, University of Freiburg, Freiburg im Breisgau, Germany.

Received: 21 February 2017 Accepted: 15 November 2017

Published online: 21 November 2017

\section{References}

1. Benavides M, Anton A, Gallego J, Gomez MA, Jimenez-Gordo A, La Casta A, Laquente B, Macarulla T, Rodriquez-Mowbray JR, Maurel J. Biliary tract cancers: SEOM clinical guidelines. Clin Transl Oncol. 2015;17(12):982-7.

2. Khan SA, Davidson BR, Goldin RD, Heaton N, Karani J, Pereira SP, Rosenberg WM, Tait P, Taylor-Robinson SD, Thillainayagam AV, et al. Guidelines for the diagnosis and treatment of cholangiocarcinoma: an update. Gut. 2012:61(12):1657-69.

3. Simo KA, Halpin LE, McBrier NM, Hessey JA, Baker E, Ross S, Swan RZ, lannitti DA, Martinie JB. Multimodality treatment of intrahepatic cholangiocarcinoma: a review. J Surg Oncol. 2016;113(1):62-83.

4. Valle J, Wasan $\mathrm{H}$, Palmer DH, Cunningham D, Anthoney A, Maraveyas A, Madhusudan S, Iveson T, Hughes S, Pereira SP, et al. Cisplatin plus Gemcitabine versus Gemcitabine for Biliary tract cancer. N Engl J Med. 2010;362(14):1273-81.

5. Carrafiello G, Laganà D, Cotta E, Mangini M, Fontana F, Bandiera F, Fugazzola C. Radiofrequency ablation of Intrahepatic Cholangiocarcinoma: preliminary experience. Cardiovasc Intervent Radiol. 2010;33(4):835-9.

6. Kiefer MV, Albert M, McNally M, Robertson M, Sun W, Fraker D, Olthoff $K$ Christians K, Pappas S, Rilling W, et al. Chemoembolization of intrahepatic cholangiocarcinoma with cisplatinum, doxorubicin, mitomycin C, ethiodol, and polyvinyl alcohol. Cancer. 2011:117(7):1498-505.

7. Schiffman SC, Metzger T, Dubel G, Andrasina T, Kralj I, Tatum C, McMasters KM, Scoggins CR, Martin RCG. Precision hepatic arterial Irinotecan therapy in the treatment of unresectable intrahepatic cholangiocellular carcinoma: optimal tolerance and prolonged overall survival. Ann Surg Oncol. 2011;18(2):431-8.

8. Mouli S, Memon K, Baker T, Benson lii AB, Mulcahy MF, Gupta R, Ryu RK, Salem R, Lewandowski RJ. Yttrium-90 radioembolization for intrahepatic cholangiocarcinoma: safety, response, and survival analysis. J Vasc Intery Radiol. 2013;24(8):1227-34.

9. Mambrini A, Guglielmi A, Pacetti P, lacono C, Torri T, Auci A, Nicoli N, Orlandi M, Guadagni S, Fiorentini G, et al. Capecitabine plus hepatic intraarterial epirubicin and cisplatin in unresectable biliary cancer: a phase II study. Anticancer Res. 2007;27(4C):3009-13.

10. Becker NS, Rodriguez JA, Barshes NR, O'Mahony CA, Goss JA, Aloia TA Outcomes analysis for 280 patients with Cholangiocarcinoma treated with liver transplantation over an 18-year period. J Gastrointest Surg. 2008:12(1):117-22.

11. Ortner ME, Caca K, Berr F. Successful photodynamic therapy for nonresectable cholangiocarcinoma: a randomized prospective study. Gastroenterology. 2003;125:1355-63.

12. Tao R, Krishnan S, Bhosale PR, Javle MM, Aloia TA, Shroff RT, Kaseb AO, Bishop AJ, Swanick CW, Koay EJ, et al. Ablative radiotherapy doses lead to a substantial prolongation of survival in patients with inoperable Intrahepatic Cholangiocarcinoma: a retrospective dose response analysis. J Clin Oncol Off J Am Soc Clin Oncol. 2015:34:219-226.

13. Shinohara ET, Mitra N, Guo M, Metz JM. Radiation therapy is associated with improved survival in the adjuvant and definitive treatment of intrahepatic cholangiocarcinoma. Int J Radiat Oncol Biol Phys. 2008; 72(5):1495-501.

14. Crane CH, Macdonald KO, Vauthey JN, Yehuda P, Brown T, Curley S, Wong A, Delclos M, Charnsangavej C, Janjan NA. Limitations of conventional doses of chemoradiation for unresectable biliary cancer. Int J Radiat Oncol Biol Phys. 2002;53(4):969-74.

15. Sterzing F, Brunner TB, Ernst I, Baus WW, Greve B, Herfarth K, Guckenberger M. Stereotactic body radiotherapy for liver tumors: principles and practical guidelines of the DEGRO working group on stereotactic radiotherapy. Strahlenther Onkol. 2014;190(10):872-81. 
16. Mendez Romero A, de Man RA. Stereotactic body radiation therapy for primary and metastatic liver tumors: from technological evolution to improved patient care. Best Pract Res Clin Gastroenterol. 2016;30(4):603-16.

17. Eisenhauer EA, Therasse $P$, Bogaerts J, Schwartz LH, Sargent D, Ford R, Dancey J, Arbuck S, Gwyther S, Mooney M, et al. New response evaluation criteria in solid tumours: revised RECIST guideline (version 1.1). Eur J Cancer. 2009;45(2):228-47.

18. Gkika E, Adebahr S, Kirste S, Schimek-Jasch T, Wiehle R, Claus R, Wittel U, Nestle $U$, Baltas D, Grosu AL, et al. Stereotactic body radiotherapy (SBRT) in recurrent or oligometastatic pancreatic cancer. Strahlenther Onkol. 2017:1-10.

19. Timmerman RD. An overview of hypofractionation and introduction to this issue of seminars in radiation oncology. Semin Radiat Oncol. 2008;18(4):215-22.

20. Brunner TB, Nestle U, Adebahr S, Gkika E, Wiehle R, Baltas D, Grosu AL: Simultaneous integrated protection: A new concept for high-precision radiation therapy. Strahlentherapie und Onkologie: Organ der Deutschen Rontgengesellschaft [et al] 2016;192:886-895.

21. Fowler JF, Tome WA, Fenwick JD, Mehta MP. A challenge to traditional radiation oncology. Int J Radiat Oncol Biol Phys. 2004;60(4):1241-56.

22. Momm F, Schubert E, Henne K, Hodapp N, Frommhold H, Harder J, Grosu AL, Becker G. Stereotactic fractionated radiotherapy for Klatskin tumours. Radiother Oncol. 2010;95(1):99-102.

23. Kirste $\mathrm{S}$, Trautsch $\mathrm{H}$. Abdominal stereotactic body radiotherapy: local control and correlation to biologically equivalent dose. OMICS J Radiol. 2016;05(02):1-7.

24. Brunner TB, Seufferlein T. Radiation therapy in cholangiocellular carcinomas. Best Pract Res Clin Gastroenterol. 2016;30(4):593-602.

25. Jung DH, Kim MS, Cho CK, Yoo HJ, Jang WI, Seo YS, Paik EK, Kim KB, Han CJ, Kim SB. Outcomes of stereotactic body radiotherapy for unresectable primary or recurrent cholangiocarcinoma. Radiat Oncol J. 2014;32(3):163-9.

26. Sandler KA, Veruttipong D, Agopian VG, Finn RS, Hong JC, Kaldas FM, Sadeghi S, Busuttil RW, Lee P. Stereotactic body radiotherapy (SBRT) for locally advanced Extrahepatic and Intrahepatic Cholangiocarcinoma. Adv Radiat Oncol. 2016:1:237-243.

27. Kopek N, Holt MI, Hansen AT, Hoyer M. Stereotactic body radiotherapy for unresectable cholangiocarcinoma. Radiother Oncol. 2010;94(1):47-52.

28. Polistina FA, Guglielmi R, Baiocchi C, Francescon P, Scalchi P, Febbraro A, Costantin G, Ambrosino G. Chemoradiation treatment with gemcitabine plus stereotactic body radiotherapy for unresectable, non-metastatic, locally advanced hilar cholangiocarcinoma. Results of a five year experience. Radiother Oncol. 2011;99(2):120-3.

29. Goodman KA, Wiegner EA, Maturen KE, Zhang Z, Mo Q, Yang G, Gibbs IC, Fisher GA, Koong AC. Dose-escalation study of single-fraction stereotactic body radiotherapy for liver malignancies. Int J Radiat Oncol Biol Phys. 2010;78(2):486-93.

30. Mahadevan A, Dagoglu N, Mancias J, Raven K, Khwaja K, Tseng JF, Ng K, Enzinger $P$, Miksad R, Bullock A, et al. Stereotactic body radiotherapy (SBRT) for Intrahepatic and Hilar Cholangiocarcinoma. J Cancer. 2015;6(11):1099-104.

31. Pollom EL, Alagappan M, Park LS, Whittemore AS, Koong AC, Chang DT. Does radiotherapy still have a role in unresected biliary tract cancer? Cancer Med. 2016; 6:129-141

32. Klein J, Dawson LA, Jiang H, Kim J, Dinniwell R, Brierley J, Wong R, Lockwood G, Ringash J. Prospective longitudinal assessment of quality of life for liver cancer patients treated with stereotactic body radiation therapy. Int J Radiat Oncol Biol Phys. 2015;93(1):16-25.

33. Mendez Romero A, Wunderink W, van Os RM, Nowak PJ, Heijmen BJ, Nuyttens JJ, Brandwijk RP, Verhoef C, ljzermans JN, Levendag PC. Quality of life after stereotactic body radiation therapy for primary and metastatic liver tumors. Int J Radiat Oncol Biol Phys. 2008;70(5):1447-52.

34. Tse RV, Hawkins M, Lockwood G, Kim JJ, Cummings B, Knox J, Sherman M, Dawson LA. Phase I study of individualized stereotactic body radiotherapy for hepatocellular carcinoma and intrahepatic cholangiocarcinoma. J Clin Oncol. 2008;26(4):657-64.

35. Ibarra RA, Rojas D, Snyder L, Yao M, Fabien J, Milano M, Katz A, Goodman K, Stephans K, El-Gazzaz G, et al. Multicenter results of stereotactic body radiotherapy (SBRT) for non-resectable primary liver tumors. Acta Oncol. 2012;51(5):575-83.

36. Barney BM, Olivier KR, Miller RC, Haddock MG. Clinical outcomes and toxicity using stereotactic body radiotherapy (SBRT) for advanced cholangiocarcinoma. Radiat Oncol. 2012;7(1):67.

37. Weiner AA, Olsen J, Ma D, Dyk P, DeWees T, Myerson RJ, Parikh P. Stereotactic body radiotherapy for primary hepatic malignancies - report of a phase I/II institutional study. Radiother Oncol. 2016;121:79-85.

\section{Submit your next manuscript to BioMed Central and we will help you at every step:}

- We accept pre-submission inquiries

- Our selector tool helps you to find the most relevant journal

- We provide round the clock customer support

- Convenient online submission

- Thorough peer review

- Inclusion in PubMed and all major indexing services

- Maximum visibility for your research

Submit your manuscript at www.biomedcentral.com/submit 